Kalpa Publications in Engineering
Volume 1, 2017, Pages 316-325
ICRISET2017. International Conference on Re-
search and Innovations in Science, Engineering
\&Technology. Selected Papers in Engineering $\quad$ kalpe

\title{
Numerical Investigation on Thermal Conductivity of Vapor Chamber by Using Iterative Approach
}

\author{
${ }^{1}$ Deepak Jani, ${ }^{2}$ Ajit Chaudhari, ${ }^{3}$ Mukesh Keshwani, ${ }^{3}$ Amarish Badgujar.
}

\author{
${ }^{1}$ Electronic and Mechanical Engineering School, ${ }^{2}$ Mechanical Engineering Department \\ Sigma Institute of Engineering and Technology, ${ }^{3}$ Mechanical Engineering Department SET, \\ Navrachana University Vadodara, India \\ janideepak17@yahoo.in, ajit2126@gmail.com, mukeshkeshwani@gmail.com, \\ amarishb@nuv.ac.in
}

\begin{abstract}
Technological developments have resulted in a growing demand for high power electronic devices. Although these high power devices meet the high performance requirements, they also generate a very large amount of heat which adversely affects their operating efficiency. Most part of the heat within a package is generated at the chip and hence it is important to keep junction temperature as low as possible. This is commonly achieved by using heat sinks mounted directly on top of the package. Using a vapor chamber can reduce thermal resistance by better spreading heat across the heat sink base. This work presents a parametric study of vapor chambers as heat spreaders and discusses the merits of using this technology especially in high power devices through CFD modeling. Iterative method is used to finalize the value of Ks and $\mathrm{Kl}$ by considering the orthotropic approach.
\end{abstract}

Keywords-Vapor chamber, CFD, Iterative Method, Heat removal 


\section{Introduction}

There are many available models to analyze the performances of the heat pipes. By assuming that the central core being occupied by vapor, and the wicks are being filled with liquid, Faghri and Chen [1], and Faghri [2] solved the governing equations of the internal flow field and the associated heat transfer. The pressure-momentum interaction of the internal flow was taken into account, and the mass and energy exchanges across the liquid-vapor interface were modeled in accordance with the conservation of mass and energy. Tournier and El-Genk [3] also developed a two-dimensional model for fully thawed heat pipes. Vadakkan et al. [4] solved the internal flow field and temperature distribution of a flat heat pipe which was heated and cooled at the same side. Koito et al. [5] solved the flow and temperature distributions within a vapor chamber, and their calculated results were in good agreement with the experiment data. Lefèvre and Lallemand [6] developed a two dimensional hydrodynamic model coupled with a three-dimensional heat conduction model to analyze the performances of flat micro heat pipes. Carbajal et al. [7] developed a two-dimensional model to investigate the thermal response of a flat heat pipe next to a local heat source

\section{Vapor Chamber}

Ultra-thin vapor chamber is simulating to evaluate heat spreading performance over copper heat spreader. Vapor space is accommodating inside copper housing within wick structure shown in Figure 1. Silicon is considered as heat flux source while top surface of vapor chamber act as convective heat transfer surface.

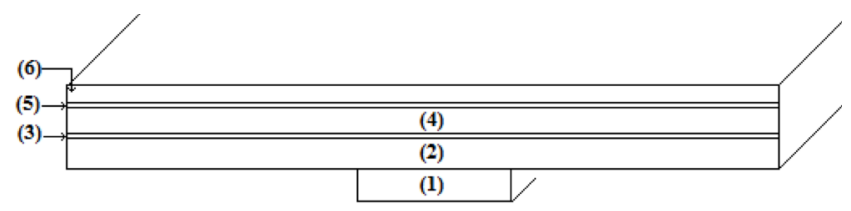

Fig. 1 Schematic diagram of vapor chamber with layer assembly

TABLEI. DIMENSION OF VARIOUS LAYERS OF VAPOR CHAMBER

\begin{tabular}{|r|l|l|}
\multicolumn{1}{|c|}{ Sr. } & Part & Dimension(mm) \\
No. & & $10 \times 10 \times 1$ \\
\hline 1 & Chip & $100 \times 100 \times 0.5$ \\
\hline 2 & VC bottom wall & $100 \times 100 \times 0.1$ \\
\hline 3 & Bottom Wick & $100 \times 100 \times 0.5$ \\
\hline 4 & Vapor core & $100 \times 100 \times 0.1$ \\
\hline 5 & Top Wick & $100 \times 100 \times 0.15$ \\
\hline 6 & VC top wall & \\
\hline
\end{tabular}




\section{Model setup in Ansys Workbach}

Boundary conditions:

- Bottom surface

Heat flux condition is apply at bottom chip surface

$$
\mathrm{q}=-\mathrm{k}_{\mathrm{si}} \frac{\mathrm{dT}}{\mathrm{dy}}
$$

Where $\mathrm{q}=$ Heat flux at bottom surface $=100 \mathrm{~W} / \mathrm{cm}^{2}$

$\mathrm{ksi}=$ thermal conductivity of Silicon

- Top surface

Convection heat transfer is assign at top surface

$$
-\mathrm{k}_{\mathrm{cu}} \frac{\mathrm{dT}}{\mathrm{dy}}=\mathrm{h}\left(\mathrm{T}_{\mathrm{s}}-\mathrm{T}_{\infty}\right)
$$

Where $\mathrm{h}=$ heat transfer coefficient in $\mathrm{W} / \mathrm{m}^{2} \mathrm{~K}=1000 \mathrm{~W} / \mathrm{m}^{2} \mathrm{~K}$

- Interface

Since silicon chip connected to vapor chamber bottom surface, conduction heat transfer is taken place at interface generated between them.

$$
-\mathrm{k}_{\mathrm{si}} \mathrm{A}_{\mathrm{si}} \frac{\mathrm{dT}}{\mathrm{dy}}=-\mathrm{k}_{\mathrm{cu}} \mathrm{A}_{\mathrm{cu}} \frac{\mathrm{dT}}{\mathrm{dy}}
$$

Similar conduction heat transfer boundary condition is assign between different layer of Vapor chamber, i.e. (1) VC bottom surface \& bottom wick surface (2) Bottom wick surface \& vapor surface (3) Vapor surface \& Top wick surface (4) Top wick surface \& VC top surface.

- Insulated wall: Remaining all outer edge is define as insulated wall where heat flux value $\mathrm{q}=0 \mathrm{~W} / \mathrm{cm} 2$.

Conductivity of Vapor space

In present study a novel technique has been proposed to find effective thermal conductivity of vapor space. Effective thermal conductivity for vapor chambers of the remote 
cooling mode has been derived in Prasher [1] based on the ideal gas law and Clapevron equation for incompressible laminar flow conditions.

$$
\mathrm{K}_{\mathrm{vapor}}=\frac{\mathrm{H}_{\mathrm{fg}}^{2} \mathrm{P} \rho \mathrm{d}^{2}}{12 \mathrm{R} \mu \mathrm{T}^{2}}
$$

Above equation captures the temperature dependency of the thermal conductivity quite well, but it is not convenient to use in the commercial design tools such as ANSYS because of the multiple thermo-physical properties usually available in tabular format. In the present study, equation (2) is first used to generate the thermal conductivity value, which is then used as initial conductivity in orthotropic approach with iterative method.

Orthotropic approach

The surface temperature distribution of the vapor chamber is more flattened than the conduction plates, as observed by Chen et al. [2]. Therefore, the orthotropic approach will be a better way to present the heat-transfer behavior of the vapor chambers. In the orthotropic approach, the effective thermal conductivity is assumed to be composed of two components: namely the straightforward conductivity and the lateral conductivity. In this study, the straightforward direction is along $\mathrm{Y}$-axis and the lateral direction is perpendicular to the straightforward direction (X- and Z-axis). The straightforward conductivity can be simply obtained from the one-dimensional resistance of the vapor chamber:

$$
\mathrm{k}_{\mathrm{s}}=\frac{\mathrm{t}}{\mathrm{R}_{1 \mathrm{D}, \mathrm{vc}} \mathrm{A}_{\mathrm{vc}}}
$$

$$
\begin{aligned}
& \text { Where } \mathrm{t}=\text { thickness of vapor space (in present case } \mathrm{t}=0.0005 \mathrm{~m}) \\
& \mathrm{Avc}=\text { Cross sectional area of vapor chamber (i.e. } 0.1 \mathrm{~m} \times 0.1 \mathrm{~m}=0.01 \mathrm{~m} 2 \text { ) } \\
& \& \mathrm{R}_{1 \mathrm{D}, \mathrm{vc}}=\frac{\Delta \mathrm{T}}{\mathrm{Q}}=\frac{\left(\mathrm{T}_{\mathrm{es}}-\mathrm{T}_{\mathrm{cs}}\right)}{\mathrm{Q}} \\
& \text { Where } \mathrm{Q}=\text { Heat in Watt (In present case } \mathrm{Q}=100 \mathrm{~W} \\
& \mathrm{~K} 1=21.08 \times \mathrm{Ks}
\end{aligned}
$$

In this method Simulation start with using conductivity of vapor space calculated with equation (2). Obtained result used in orthotropic approach. Temperature difference in bottom and top wick is calculated and with equation (3), (4) \& (5) $\mathrm{k}_{\mathrm{s}} \& \mathrm{k}_{1}$ is calculated. Now 
calculated conductivity used with orthotropic approach (Where both $\mathrm{k}_{\mathrm{s}}$ and $\mathrm{k}_{\mathrm{l}}$ is applied). Again average condenser and evaporator temperature has been calculated. This will continue till residual are very small.

Iteration-1:

Iteration process start with considering conductivity of vapor space $\mathrm{K}=2870 \mathrm{~W} / \mathrm{mK}$, Evaporator side \& condenser side average wick temperature has been obtained through simulation. With calculated temperature difference orthotropic conductivity has been obtained listed in table-2.

Simulation has been carried out with $\mathrm{q}=100 \mathrm{~W} / \mathrm{cm} 2, \mathrm{~h}=1000 \mathrm{~W} / \mathrm{m} 2 \mathrm{~K}$, While during calculation $\mathrm{Q}=100 \mathrm{~W}$,

$\mathrm{t}=0.0005 \mathrm{~m}, \mathrm{Avc}=0.01 \mathrm{~m}^{2}, \mathrm{Kl} / \mathrm{Ks}=21.08$ is considered.

\begin{tabular}{|c|c|c|c|c|c|c|c|c|}
\hline $\begin{array}{l}\text { Iteratio } \\
\text { n No }\end{array}$ & $\begin{array}{c}\mathbf{K} \\
(\mathbf{W} / \mathbf{m K} \\
)^{2}\end{array}$ & $\begin{array}{l}\mathrm{Tj} \\
\left({ }^{\circ} \mathbf{C}\right)\end{array}$ & $\begin{array}{l}\text { Tes } \\
\left({ }^{\circ} \mathrm{C}\right)\end{array}$ & $\operatorname{Tes}\left({ }^{\circ} \mathrm{C}\right)$ & $\Delta \mathbf{T}$ & $\mathbf{R}_{1 \mathrm{DVC}}$ & $\begin{array}{c}\mathbf{K s} \\
(\mathbf{W} / \mathbf{m} \mathbf{K})\end{array}$ & $\begin{array}{c}\mathbf{K l} \\
(\mathbf{W} / \mathbf{m K})\end{array}$ \\
\hline 1 & $\begin{array}{l}287 \\
0\end{array}$ & $\begin{array}{c}57.2 \\
3\end{array}$ & 35.828 & $\begin{array}{l}35.77 \\
9\end{array}$ & $\begin{array}{l}0.04 \\
9\end{array}$ & $\begin{array}{l}0.0004 \\
9\end{array}$ & $\begin{array}{l}102.0 \\
4\end{array}$ & $\begin{array}{c}2151.0 \\
2\end{array}$ \\
\hline
\end{tabular}

Where

$\mathrm{Tj}=$ Junction temperature

Tes $=$ Average temperature of evaporator section

$\mathrm{Tcs}=$ Average temperature of condenser section

\section{Iteration-2:}

Now simulation has been carried out with orthotropic thermal conductivity at vapor space i.e. $\mathrm{Ks}=102.04 \mathrm{~W} / \mathrm{mK}$ and $\mathrm{Kl}=2151.02 \mathrm{~W} / \mathrm{mK}$

\section{Table-3}

\begin{tabular}{|c|c|c|c|c|c|c|c|c|c|}
\hline $\begin{array}{l}\text { It. } \\
\text { No }\end{array}$ & $\begin{array}{c}\mathbf{K s} \\
(\mathbf{W} / \mathbf{m K} \\
)\end{array}$ & $\begin{array}{c}\mathbf{K l} \\
(\mathbf{W} / \mathbf{m K})\end{array}$ & $\mathbf{T j}\left({ }^{\circ} \mathbf{C}\right)$ & $\begin{array}{c}\mathbf{T e s} \\
\left({ }^{\circ} \mathbf{C}\right)\end{array}$ & $\begin{array}{c}\mathbf{T c s} \\
\left({ }^{\circ} \mathbf{C}\right)\end{array}$ & $\Delta \mathbf{T}$ & $\begin{array}{c}\mathbf{R}_{\mathbf{1 D}} \\
\mathbf{v C}\end{array}$ & $\begin{array}{c}\mathbf{K s} \\
(\mathbf{W} / \mathbf{m} \\
\mathbf{K})\end{array}$ & $\begin{array}{c}\mathbf{K I} \\
(\mathbf{W} / \mathbf{m} \\
\mathbf{K})\end{array}$ \\
\hline 2 & 102. & 2151. & 62. & 36. & 36. & 0.2 & 0.002 & 20. & 430 \\
\hline & 04 & 02 & 53 & 84 & 59 & 45 & 45 & 41 & .2 \\
\hline
\end{tabular}

$$
\% \text { Deviation }=\left[\frac{T_{e s_{2}}-T_{e s_{1}}}{T_{e s_{1}}}\right] \times 100=2.83
$$




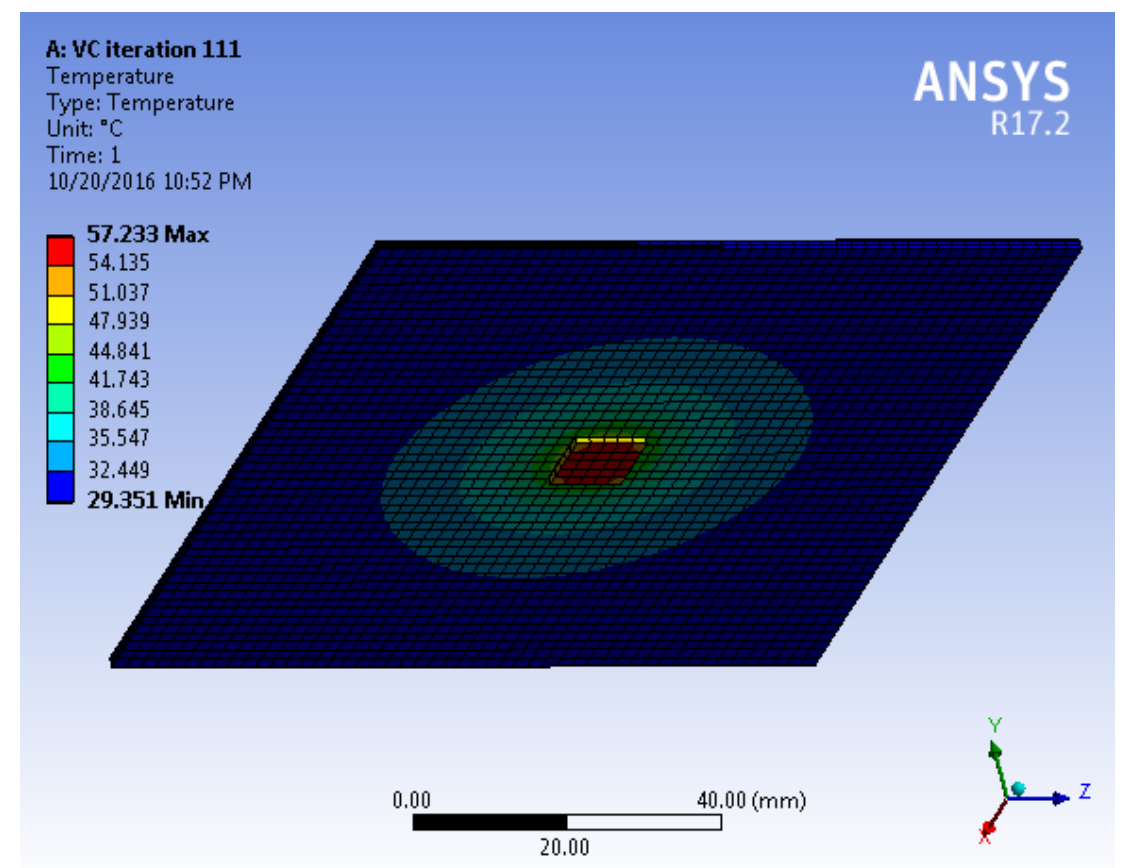

Figure-2 Temperature contour for Iteration-1, K=2780 W/mK

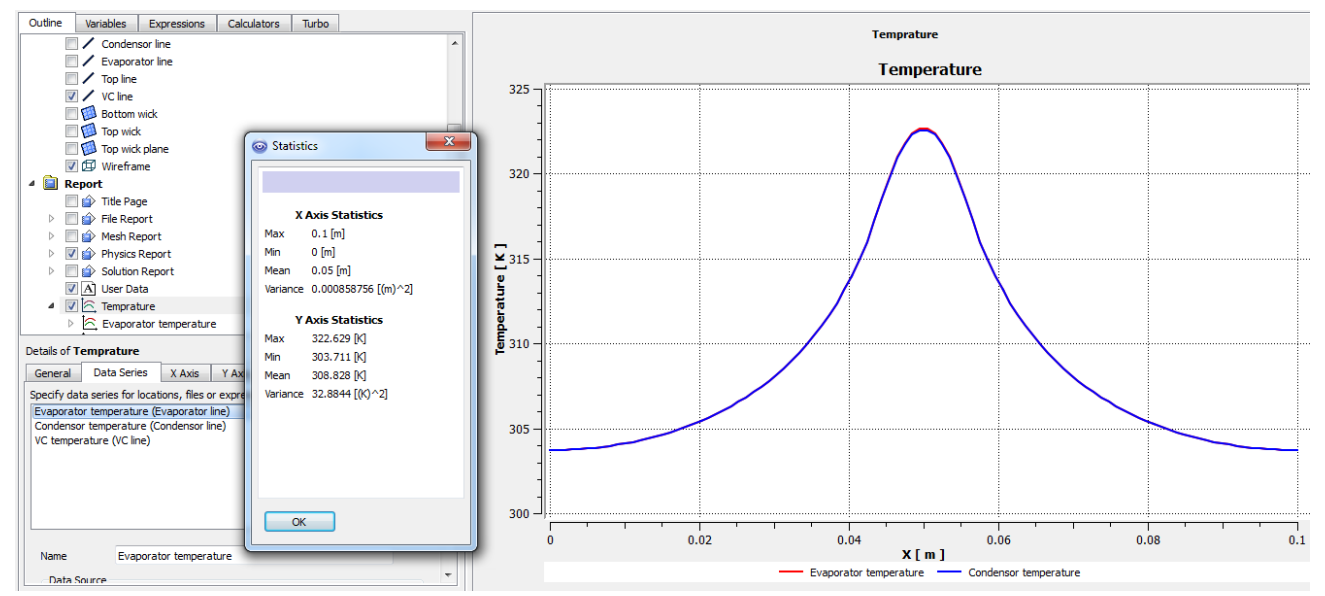

Figure 3 Snap shot for calculation of average evaporator side wick temperature 


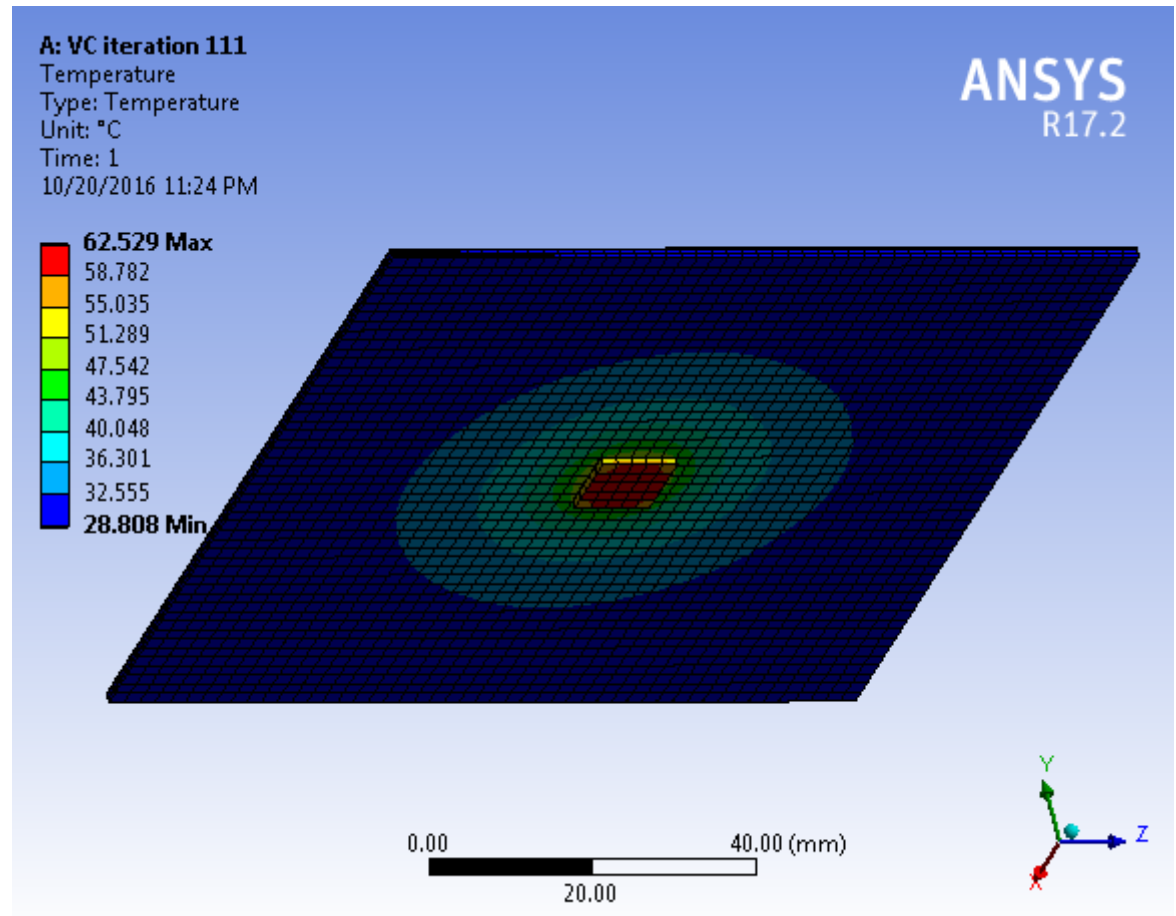

Figure-4 Temperature contour for Iteration-2, $\mathrm{Ks}=102.04 \mathrm{~W} / \mathrm{mK}, \mathrm{Kl}=2151.02$ $\mathrm{W} / \mathrm{mK}$

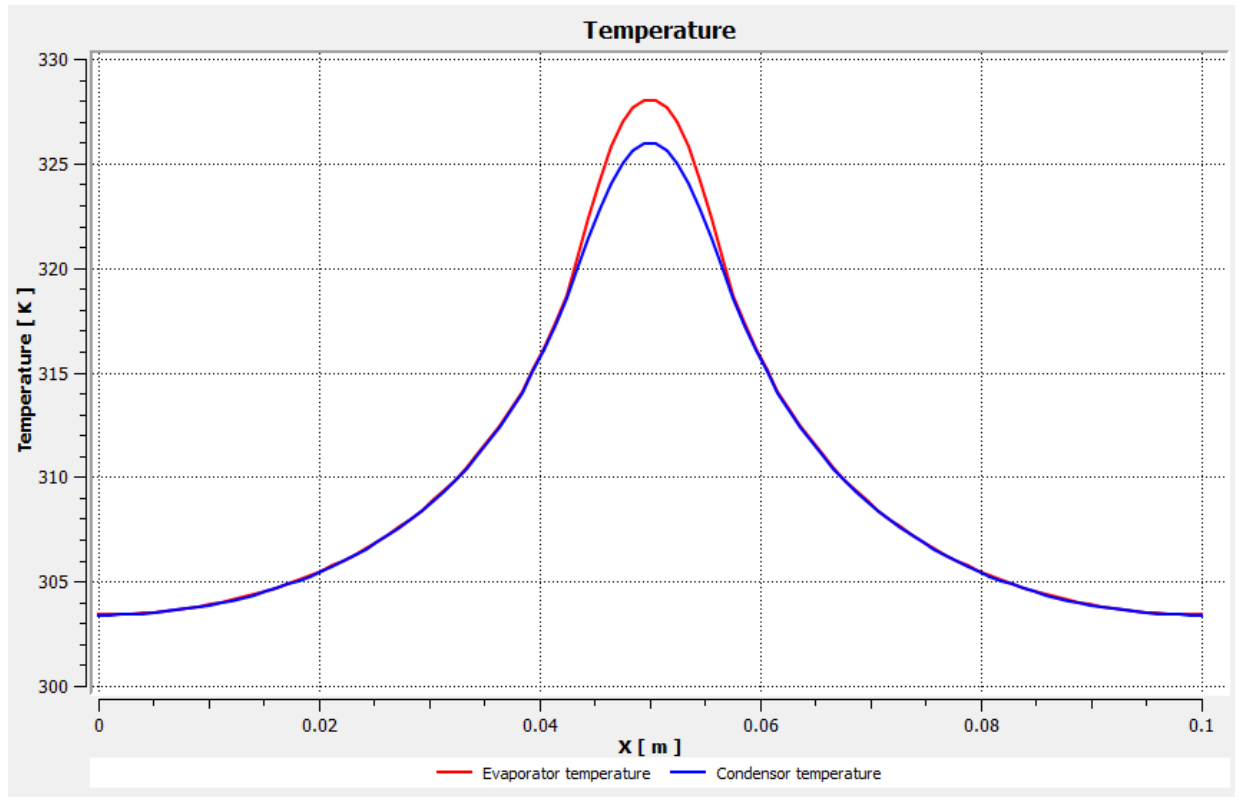


Figure-5 Temperature profile along lateral direction at evaporator \& condenser side wick for Iteration-2

\section{Iteration-3:}

Table-4

\begin{tabular}{|c|c|c|c|c|c|c|c|c|c|}
\hline $\begin{array}{l}\text { It. } \\
\text { No }\end{array}$ & $\begin{array}{r}\mathbf{K s} \\
(\mathbf{W} / \mathbf{m K}) \\
\end{array}$ & $\begin{array}{r}\mathbf{K l} \\
(\mathbf{W} / \mathbf{m K}) \\
\end{array}$ & $\begin{array}{r}\mathbf{T j} \\
\left({ }^{\circ} \mathrm{C}\right) \\
\end{array}$ & $\begin{array}{c}\text { Tes } \\
\left({ }^{\circ} \mathrm{C}\right) \\
\end{array}$ & $\begin{array}{c}\text { Tes } \\
\left({ }^{\circ} \mathrm{C}\right) \\
\end{array}$ & $\Delta \mathbf{T}$ & $\mathbf{R}_{1 \mathrm{D} \mathrm{vC}}$ & $\begin{array}{c}\mathbf{K s} \\
(\mathbf{W} / \mathbf{m K}) \\
\end{array}$ & $\begin{array}{l}\text { Kl } \\
(\mathbf{W} / \mathbf{m K})\end{array}$ \\
\hline 3 & 20.41 & 430.2 & 95.1 & 43.187 & 42.111 & 1.076 & 0.01076 & 4.65 & 97.96 \\
\hline
\end{tabular}

$$
\% \text { Deviation }=\left[\frac{T_{e s_{3}}-T_{e s_{2}}}{T_{e s_{2}}}\right] \times 100=17.22
$$

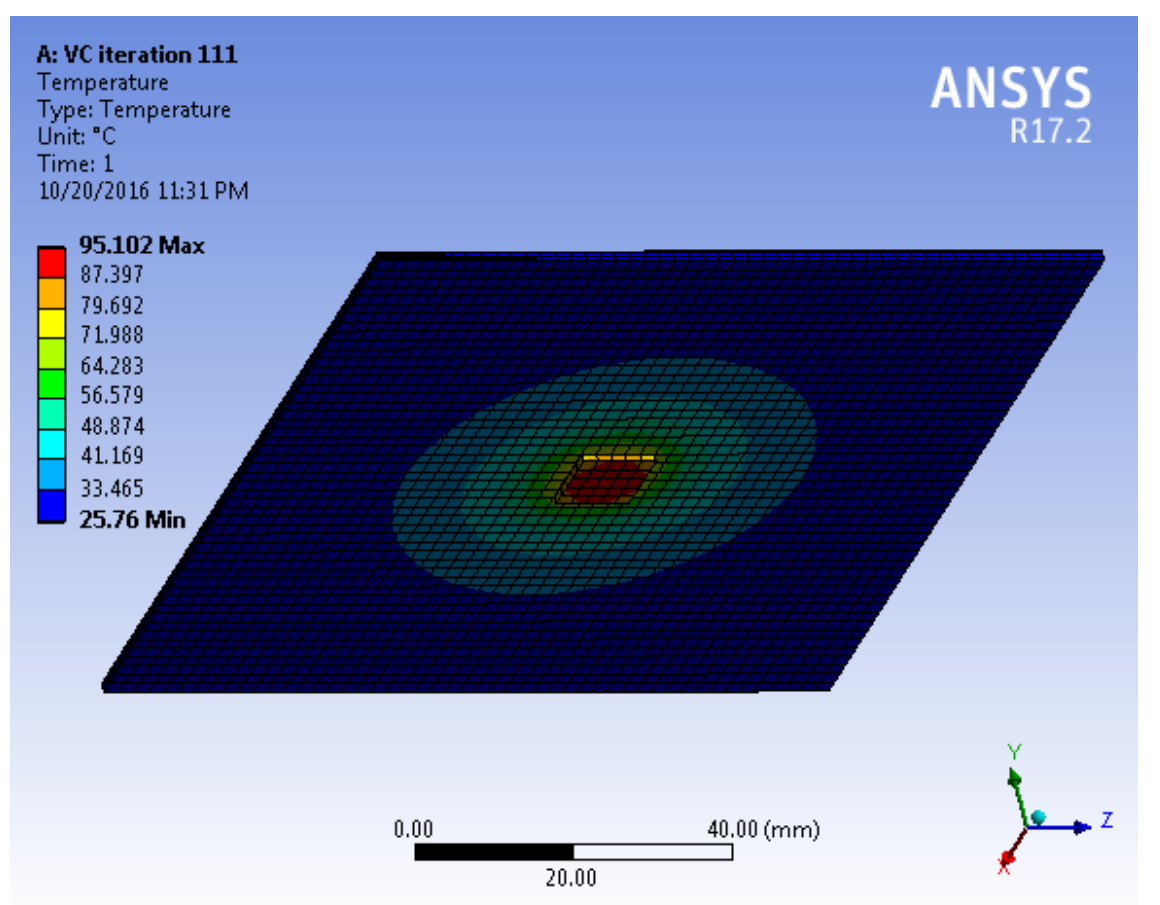

Figure-6 Temperature contour for Iteration-3, $\mathrm{Ks}=20.41 \mathrm{~W} / \mathrm{mK}$,

$$
\mathrm{Kl}=430.2 \mathrm{~W} / \mathrm{mK}
$$




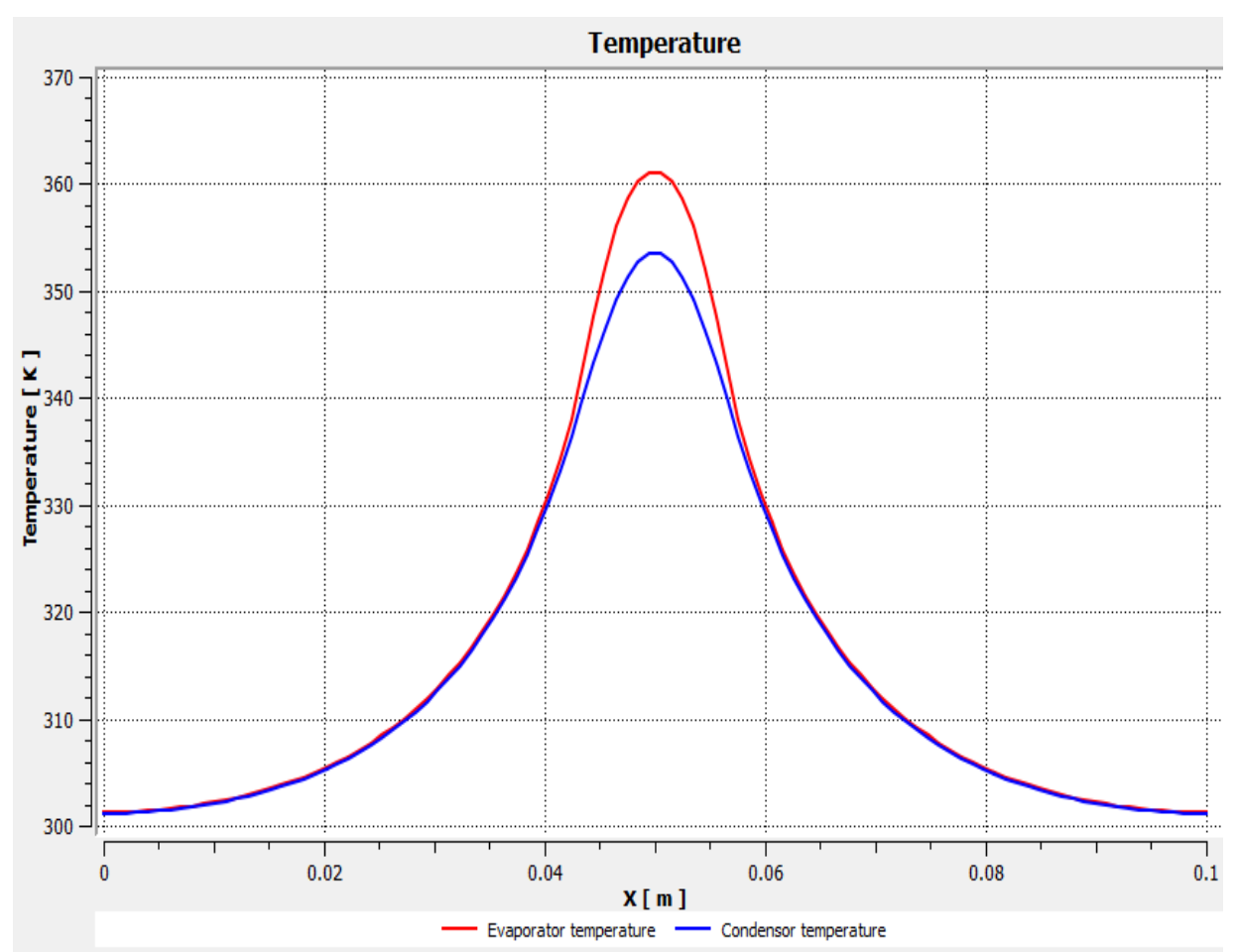

Figure-6 Temperature profile along lateral direction at evaporator \& condenser side wick for Iteration-3

\section{Conclusion}

From the above results it can be concluded that to obtain the value of thermal conductivity in vapor space using orthotropic approach, iterative method has to be used. Initially, Clayperon equation helps in determining the thermal conductivity of vapor space which can be applied to resistance approach to determine average temperature as two wick levels. This is further utilized in obtaining straight forward and lateral thermal conductivity. Iterative process will lead to deviation in wick temperature to minimum will be final value of Ks and Kl. From the simulation 2nd iteration the \% deviation is 2.83 which is minimum. Hence, it has been suggested that orthotropic conductivity for vapor space according to iterative method should be: $\mathrm{Ks}=102.04 \mathrm{~W} / \mathrm{mK} \& \mathrm{Kl}=2151.02 \mathrm{~W} / \mathrm{mK}$ which can be further used to simulate the heat transfer phenomena in vapor chamber.

\section{References}

[1] A. Faghri, M.M. Chen, A numerical analysis of the effects of conjugate heat transfer, vapor compressibility, and viscous dissipation in heat pipes,Numerical Heat Transfer Part A 16 (3) (1989) 389-405

[2] A. Faghri, Heat Pipe Science and Technology, Taylor \& Francis, USA, 1995.

[3] J.M. Tournier, M.S. El-Genk, A heat pipe transient analysis model, International Journal of Heat and Mass Transfer 37 (5) (1994) 753-762.

[4] U. Vadakkan, S.V. Garimella, J.Y. Murthy, Transport in flat heat pipes at high fluxes from multiple discrete sources, Transaction of ASME, Journal of Heat Transfer 126 (2004) 347-354. 
[5] Y. Koito, H. Imura, M. Mochizuki, Y. Saito, S. Torii, Numerical analysis and experimental verification on thermal fluid phenomena in a vapor chamber, Applied Thermal Engineering 26 (2006) 1669-1676.

[6] F. Lefèvre, M. Lallemand, Coupled thermal and hydrodynamic models of flat micro heat pipes for the cooling of multiple electronic components, International Journal of Heat and Mass Transfer 49 (2006) 1375-1383.

[7] G. Carbajal, C.B. Sobhan, G.P. Peterson, D.T. Queheillalt, H.N.G. Wadley, Thermal response of a flat heat pipe sandwich structure to a localized heat flux, International Journal of Heat and Mass Transfer 49 (2006) 4070-4081.

[8] Swapnil Patel, Mehul Bambhania, Numerical simulation of copper heat spreader used in electronics chip cooling, International Conference on Futuristic Trends in Engineering, Science, Pharmacy and Management,274-280(2016). 